\title{
Desfiar a poética do tecido
}

\author{
Vivian Morizono \\ Yuri Cerqueira dos Anjos ${ }^{2}$ \\ Aline Magalhães dos Santos ${ }^{3}$
}

\begin{abstract}
A moda, com toda sua tirania, faz sua aparição ; se assim quiseres, iremos consagrar a ela alguns instantes de nossos lazeres, faremos o nosso melhor para tentar explicá-la. Num primeiro momento, seria possível convencer-se de que as modificações que ela trouxe este ano são de menor importância ; que o vestido do ano passado poderia, a rigor, se equivaler àquele que acaba de eclodir com a nova estação. Ah! se não houvesse as nuances! Mas elas são tantas! Étoile Filante (Marcel Proust) ${ }^{4}$
\end{abstract}

Há costura possível entre moda e literatura? Se sim, qual seu ponto, qual seu corte, seu modelo, sua função? Essas são algumas perguntas que basearam a formulação desse número da revista Criação \& Crítica.

Com "Todo mundo e Ninguém" e a "A Cobra que ri", o estilista Ronaldo Fraga nos aponta uma possível resposta, instaurando em duas de suas coleções pontos de contato com referências literárias. "Todo mundo e Ninguém", retoma, no inverno de 2005, o famoso Auto da Lusitânia de Gil Vicente (posteriormente adaptado por Carlos Drummond de Andrade); em "A Cobra que ri", coleção do verão de 2007, as peças são inspiradas no livro Grande Sertão: Veredas.

As questões que colocamos de início parecem, portanto, pertinentes e atuais. Mas mais do que isso, as roupas são objeto de um debate bastante antigo. Já no século XVI Montaigne, por exemplo, usa as roupas como assunto de seus ensaios. Ele as vê sob o signo do artifício, da máscara, numa perspectiva de denúncia das aparências. A roupa tem papel fundamental que é preciso compreender:

É preciso representar devidamente nosso papel, mas como papel de um personagem emprestado. Da máscara e da aparência não é preciso fazer uma essência real, nem do estranho o próprio. Não sabemos distinguir a pele da camisa. (MONTAIGNE, 1962, v. III, 10, p. 341/989).

\footnotetext{
1 Mestranda do Departamento de Letras Modernas (FFLCH/USP). Email: <vivian.morizono@gmail.com>.

2 Doutor em Letras Modernas (FFLCH/USP). Email: <yuricanjos@gmail.com>.
}

3 Mestranda do Departamento de Letras Modernas (FFLCH/USP). Email: <aline.magalhaesdossantos@gmail.com>.

4 PROUST, Marcel. Le Mensuel Retrouvé. Edição organizada por Jérôme Prieur. Paris: Éditions des Busclats, 2012, p. 99.

Editorial: Desfiar a poética do tecido 


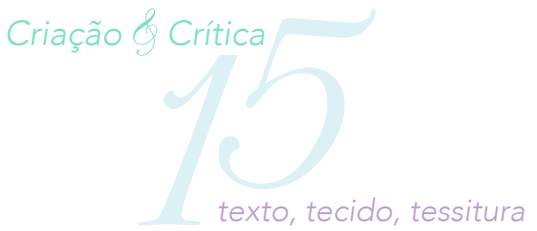

Blaise Pascal também atentava para o poder significativo das roupas. Enquanto objeto cultural, a roupa era uma representação, um meio que produzia efeitos e transmitia significados. $O$ código das roupas beneficiava aqueles que o dominavam e através dele, perscrutavam o "mistério" da relação entre o aparente e o real:

Os nossos magistrados têm conhecido bem esse mistério. As suas vestes vermelhas, os seus arminhos, que os envolvem em mantos felinos [...], todo esse augusto aparelho é muito necessário; e se os médicos não tivessem sotainas e mulas e os doutores não tivessem barretes quadrados e becas demasiado largas de quatro panos, nunca teriam enganado o mundo, que não consegue resistir a uma montra tão autêntica. (PASCAL, 1954, p. 1118)

Parte integrante do mundo social e do mundo de signos e representações que o compõe e que o moldam, as roupas - com suas formas, cores e usos - se configuram como objetos de um potencial significativo multifacetado. Se filósofos, ensaístas e historiadores se interessaram pelas roupas e pela moda, no que diz respeito à literatura- objeto específico desta edição - o interesse não é menor.

De Homero a Fernanda Young, passando por Marcel Proust- que faz da costura a imagem mesma do seu processo de criação (PROUST, 1989, p. 610) ${ }^{5}$ - os variados ângulos de abordagem e recortes presentes neste número da Criação \& Crítica são um retrato da riqueza significativa do tema "texto, tecido, tessitura". Ao caminharmos pelos diversos momentos da história das relações entre literatura e moda, perceberemos que a presença das roupas e suas metáforas traduzem um processo marcado por distinções e especificidades (variando segundo a época, a situação, o autor), mas também caracterizado por um forte traço de longa duração.

Retomando os primórdios gregos da literatura, o artigo "Vestes que falam: A tecelagem e as personagens femininas dos poemas homéricos", de Lilian Sais, mostra que em Homero as vestimentas e a tecelagem se tornam figuração da hospitalidade da comunicação, ganhando forma no exemplo de Penélope. A esposa de Ulisses passa os dias tecendo a mortalha de Laertes e, sorrateiramente, desfaz à noite todo o trabalho que produziu ao longo do dia. Essa "astúcia", empregada por Penélope no intuito de afastar seus pretendentes, pode ser considerada como uma das primeiras metáforas de poder feminino através do vestuário, em uma época onde as mulheres eram relegadas ao ambiente do lar e excluídas dos assuntos de guerra.

No Japão dos séculos X e XI, a moda será representada, novamente na literatura, como instrumento de circulação de poder. Na Era Heian, era essencial para a mulher criar a moda, saber utilizá-la, conhecer a etiqueta, possuir um estilo, ter um tecido bem cortado e tingido,

"Je bâtirais mon livre, je n'ose pas dire ambitieusement comme une cathédrale, mais tout simplement comme une robe" (PROUST, 1989, p. 610). 


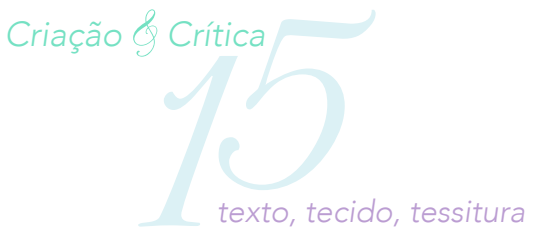

bem como conhecer a literatura e praticá-la. Esses elementos estão presentes no artigo "Texto e têxtil em $\mathbf{O}$ livro de travesseiro", de Andrei Cunha, que aborda o diário de Sei Shônagon, uma dama de honra da Corte Imperial Japonesa.

Já no século XVI, na França, Clément Marot utiliza a roupa de uma maneira diferente, transformando-a em um verdadeiro tecido constitutivo na edição da obra de François Villon, como pode ser visto no artigo "A edição de Clément Marot das obras de François Villon", de Daniel da Costa. Para Marot, o texto é como uma roupa vestida pelo autor, encobrindo o corpo/alma/intenção desse autor, no caso Villon.

Posteriormente, a moda viria a assumir um poder de sedução retórica para Pierre de Marivaux, como é discutido no artigo de Jacques Guilhembet intitulado"De la séduction textile à la séduction textuelle dans Le Paysan parvenu et La Vie de Marianne de Marivaux". O figurino se revela fundamental para o desenvolvimento dos personagens, tanto no teatro como nos romances de Marivaux.

Mercier de Compiègne foi também um pensador da moda no século XVIII, ligando-a à política, como pode ser observado no artigo "Mercier de Compiègne et la question de la mode", de Béchir Kahia. Em um ensaio lançado em 1793, momento em que as ideias e as modas sofrem consideráveis mudanças, Compiègne defende que as roupas refletem mentalidades e costumes. Por esse motivo, o autor se coloca contra os excessos e a favor da simplicidade e da beleza.

Com a chegada do século XIX, a relação entre moda e literatura será particularmente sublinhada. Na Inglaterra, temos figuras representativas como as do dândi em Beau Brummell, símbolo do homem moderno, e do escritor Oscar Wilde, que publica no final do século em Londres a revista feminina The Woman's World. Na França em 1830, Balzac publica no jornal La Mode o seu Traité de la vie élégante, reflexo do espírito aristocrático, contra a burguesia e o trabalho. Para Balzac, a elegância está ligada não só às roupas, mas a toda uma postura: ela se reflete na inteligência e engloba o portar-se e as atitudes relacionadas aos elementos sociais. Na Comédie Humaine, grande suma romanesca do século XIX, não é diferente. A percepção em torno do como se vestir e agir no ambiente social se torna um elemento constante: a roupa e o estilo colaboram para a ascensão social, como no percurso do personagem Rastignac.

Caso particularmente eloquente é o de Charles Baudelaire, considerado por Rose Fortassier como o "melhor advogado da moda" (1988, p. 91). Caminhando na contramão dos moralistas, que associavam o vestuário ao caráter efêmero e transitório, o escritor acredita que os pintores e poetas podem retirar da moda o que ela tem de poético, "o eterno do transitório". Ele vê beleza no que é visto como artificial, fruto do cálculo, como coloca, por exemplo, em seu poema "Éloge du maquillage". Posteriormente, outro poeta, Stéphane Mallarmé, também desenvolverá o tema, porém desta vez criando e tornando-se único redator (sob diversos pseudônimos) de uma revista de moda: La Dernière mode (1874).

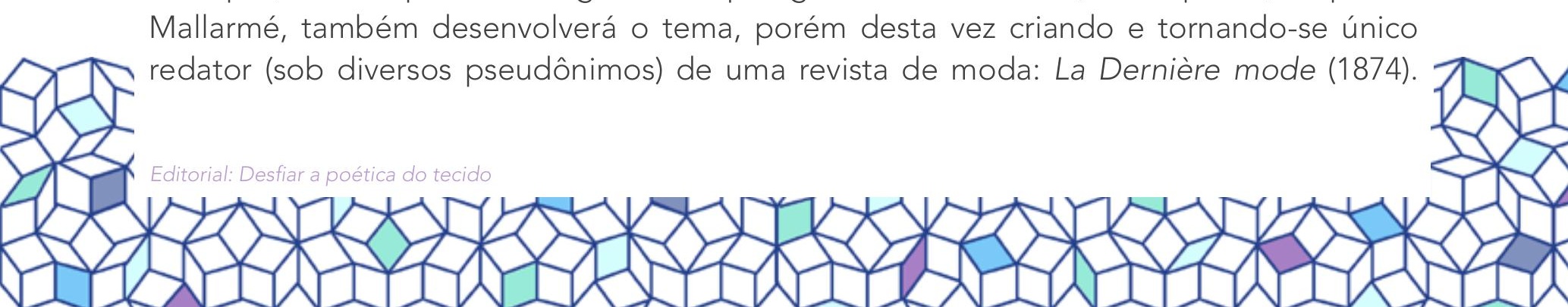


Diferente de outros autores, Mallarmé não traz a moda como objeto de análise, nem pretende integrá-la em sua visão de mundo: ele adentra nos bastidores da imprensa divulgadora dos vestuários para falar sobre o assunto.

Em terras brasileiras o tema também tomará diversas formas. Joaquim Manuel de Macedo traz a simplicidade do vestuário em A Moreninha; Machado de Assis escreve para os periódicos de moda e literatura como O Jornal das famílias e A estação, além de representar em seus romances e contos as modas do período e seus reflexos nas características dos personagens. Encontramos também em José de Alencar um grande representante da figuração do tema da moda na literatura brasileira. Estudado por Gilda de Mello e Souza (1987), o autor também é objeto do artigo "Os vestidos de Lúcia: personagem e vestuário em Lucíola de José de Alencar", de Gabriel Hernandes. Alencar representou as roupas, as modas e seus meandros em muitas de suas obras, como Lucíola, Senhora, Diva e a Pata da Gazela. Nesses romances as roupas estão estreitamente ligadas com a dimensão psicológica dos personagens criados e são reflexos de seu tempo, revelando um momento em que os códigos ligados às roupas são bastante complexos e se configuram como um ato de grande importância no jogo narrativo e interativo do contexto social figurado nos romances.

Caminhando para o século XX, chegamos à obra de Marcel Proust, em que a costura e as roupas não somente servem para traduzir a identidade dos personagens, como também produzem metáfora acerca do trabalho de construção do romance. Tais fatores são observados no artigo "O leitmotiv Fortuny e Odette: espaço e tempo na tessitura de Proust", de Bernardete Marantes. No esteio dessa reflexão vale ainda lembrar que Proust escreveu artigos de moda para o Le Mensuel e crônicas mundanas que abordam o vestuário como elemento fundamental. Segundo Fortassier (1988, p. 154), o autor tem o interesse de um cronista nas invenções de moda do dia-a-dia e é um dos primeiros, juntamente com Colette, a introduzir no romance uma enorme quantidade de novas modas e palavras relacionadas a elas.

Durante o período da Segunda Guerra, a questão moda/literatura não deixa de ser importante, como bem nos mostra o artigo de Krzysztof Trojanowski intitulado "La mode française sous l'occupation allemande dans le journal d'Andrzej Bobkowski 1940 -1944". Através do exemplo de Bobkowski, escritor e ensaísta polonês, podemos entrar em contato com a moda francesa dos "années noires": cores, formas e acessórios diversos povoam esse tenso e complexo período onde as identidades e as tomadas de posição são decisivas e transparecem nas escolhas de vestuário.

Na literatura contemporânea, que tende a buscar uma distância e um questionamento das representações, poderíamos prever um retraimento da questão da moda enquanto objeto literário. Porém, diversos artigos deste número mostram justamente o contrário.

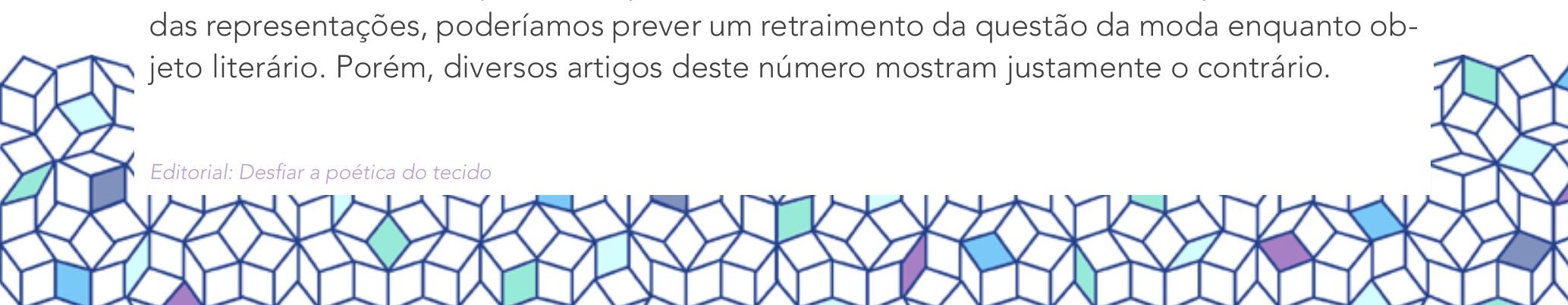




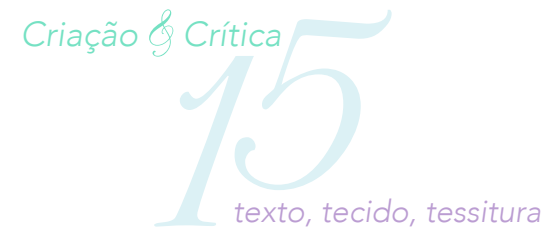

Segundo o artigo "A tecelagem lírica de uma Penélope moderna: A alquimia dos nós, de Yêda Schmaltz", de Paulo Vieira Júnior, Schmaltz propõe uma releitura dos personagens da mitologia grega e latina e, com isso, retoma a ideia do ato de tecer, já presente em Homero. Nesse caso, a mulher tece a sua própria existência e o seu livro é o produto de uma costura, onde os nós estão diretamente relacionados com a linguagem e a escrita poética.

Outro exemplo é a escritora Marina Colassanti, estudada por Enedir Santos e Kelcilene Rodrigues no artigo "O tecer e o trajar: metáforas do empoderamento feminino em dois contos de Marina Colasanti". Colassanti utiliza a moda para falar sobre o poder feminino na sociedade contemporânea, em detrimento do homem.

$\mathrm{Na}$ continuidade das escritas femininas, podemos também evocar o caso de Fernanda Young. No artigo "A sombra das vossas asas: o corpo como rascunho e projeto de si", Erica Wels mostra como essa autora usa a moda, através de seus personagens, para tratar da atualidade e de como a relação entre corpo, consumo e mídia são profundas e imbricadas.

Diante desse múltiplo quadro, fechamos a revista com uma Entrevista com o professor Guillaume Pinson (Université Laval-Canadá), feita por Yuri dos Anjos. Esse último arremate propõe um diálogo no qual se delineia um percurso de pesquisa amplamente interessado na interação de diversos âmbitos, disciplinas, corpus. Esperamos, que esse debate possa inspirar novos projetos que abordem o tecido de comunicações, representações, sociabilidades e textualidades que nos propusemos a abordar ao longo do número como um todo.

Podemos apreender, no breve percurso deste número, o fato de que a relação entre a moda e a literatura é duradoura e complexa. Através dos autores e artigos apresentados aqui, vemos que o vestuário pode trazer uma reflexão sobre a representação, o poder, o tempo, a escrita, a memória, o corpo, o gênero. Nesse sentido, o texto literário procura de certa forma fixar a roupa em suas diversas potencialidades semânticas, sociais, históricas e escriturais.

As roupas podem ser diretamente relacionadas com a construção de um personagem, suas atitudes e seu percurso na narrativa, podendo alcançar a ascensão social através da aparência que ele veicula através do que veste.

A moda pode ser evocada nas obras como um símbolo de possibilidades de comunicação, de identidade, de poderes e de impasses - seja no contexto das vivências de guerra, seja no contexto das vivências de gênero.

Por fim, o tecido pode estar no cerne mesmo de uma obra, estar encarnado no processo de criação, na organização de um projeto literário e nas figuras que compõem sua metalinguagem.

A roupa é objeto de consumo, código estabelecido, mas também compõe um espaço para a autenticidade e para a inventividade. Ela tem a sua própria temporalidade, segue o ritmo

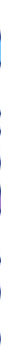


das "saisons", mas também ultrapassa a temporalidade, vive se recriando a partir de ideias do passado e se projetando como obra do futuro - costurando a (sua) própria história.

Tal qual Baudelaire, talvez possamos nos propor a extrair um pouco de eternidade de algo aparentemente transitório, efêmero, banal. Buscaremos na literatura uma significação mais ampla e complexa da moda e das roupas, desfiando uma poética do tecido que se emaranha no tear da história, da criação e da crítica.

\section{Referências}

FORTASSIER, Rose. Les écrivains français et la mode: de Balzac à nos jours. Paris: Presses universitaires de France, 1988.

LECERCLE, Jean Pierre. Mallarmé et la mode. Paris: Séguier, 2014.

PASCAL, Blaise. Oeuvres Complètes: Pensées. Paris: Gallimard, 1954.

MONTAIGNE, Michel de. Oeuvres completes: Essais - III. Paris: Gallimard, 1962.

PROUST, Marcel. À la recherche du temps perdu - IV. Paris: Gallimard, 1989.

. Le Mensuel Retrouvé. Edição organizada por Jérôme Prieur. Paris: Éditions des Bus-

clats, 2012.

SOUZA, Gilda de Mello e. O espírito das roupas: A moda no século dezenove. São Paulo: Companhia das Letras, 1987. 